\title{
Water-flow mediated oxygen dynamics within massive Porites-algal turf interactions
}

\author{
Anya L. Brown ${ }^{1,2, *}$, Robert C. Carpenter ${ }^{1}$ \\ ${ }^{1}$ California State University, 15111 Nordhoff Street, Northridge, California 91330, USA \\ ${ }^{2}$ Present address: University of Florida, Gainesville, Florida 32611, USA
}

ABSTRACT: Negative interactions between corals and algae have been implicated in preventing coral reef recovery. A recent hypothesis is that algae indirectly cause coral tissue mortality by fueling microbial growth, which drives hypoxic conditions at the interface between corals and algae. However, previous studies have largely ignored how water flow influences oxygen concentrations at the interface between corals and algae. This study quantified the effect of water flow on oxygen concentrations above the zone of interaction between massive Porites spp. and algal turf during the day and at night. Coral-algal interactions were exposed to 3 flow speeds $(0,7.7$, $14.5 \mathrm{~cm} \mathrm{~s}^{-1}$ ), and diffusive boundary layer (DBL) thicknesses were measured in the light and dark. DBL thickness $(<500$ to $2500 \mu \mathrm{m})$ decreased with increasing water flow, but remained thicker above algal turf and the zone of interaction $(\sim 1000 \mu \mathrm{m})$ than over corals $(370 \mu \mathrm{m})$ in the dark. Oxygen extremes above the zone of interaction were most similar to concentrations above algal turf in low flow (34 to $43 \%$ oxygen saturation). The influence of microbes on oxygen conditions was estimated by adding antibiotic (50 $\mu \mathrm{g}$ ampicillin $\mathrm{ml}^{-1}$ ) to algal turf-massive Porites interactions. The results showed no indication of microbially mediated hypoxic conditions. These results suggest that water flow likely limits the effectiveness of hypoxia or hyperoxia-mediated coral-algal competition under natural reef conditions.

KEY WORDS: Water flow - Oxygen concentrations · Coral-algal interactions - Microbially mediated interactions

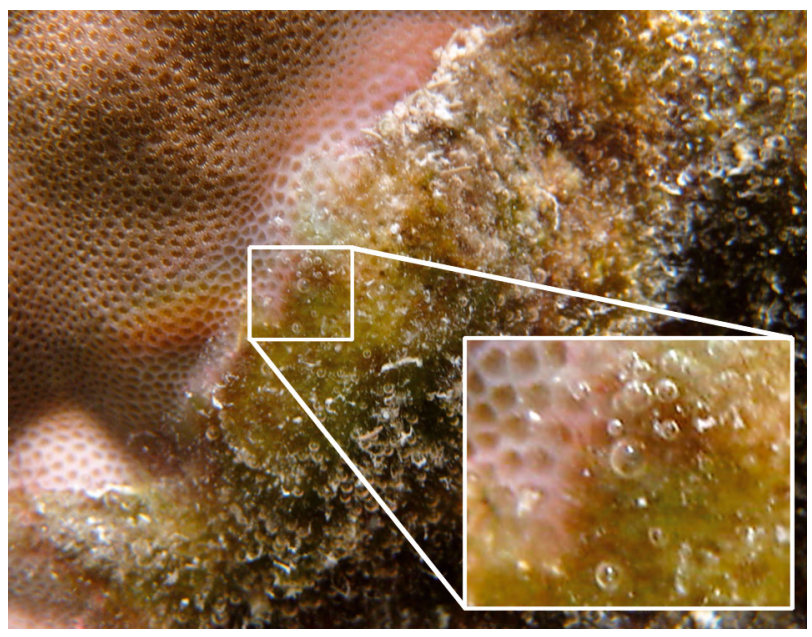

Interaction between massive Porites sp. and algal turf; note the bleached coral, as well as bubbles (inset) on the algae at the zone of interaction.

Photo: Anya Brown

\section{INTRODUCTION}

Coral reefs are structurally complex ecosystems, which host a diversity of reef-associated species and support adjacent tourism-driven economies. Reef degradation, commonly defined as a decrease in live coral cover, can lead to declines in the critical habitat on which reef-associated organisms and coastal economies depend (Moberg \& Folke 1999). Space availability, compounded by declines in herbivory and/or anthropogenic nutrient delivery, can lead to shifts in community structure from coral-dominated to algal-dominated communities (Hughes 1994, Bellwood et al. 2004, Bruno et al. 2009), thus increasing the potential for coral-algal interactions. 
Algal contact with coral can lead to polyp retraction, coral tissue death, decreased photosynthesis at the point of coral-algal contact, and disease (River \& Edmunds 2001, Jompa \& McCook 2003, Nugues et al. 2004, Rasher \& Hay 2010a,b). The mechanisms underlying the effects of algae on corals include abrasion, shading, pre-emptive colonization, overgrowth, disease, or allelopathy (McCook et al. 2001). A newly proposed mechanism underlying coralalgal interactions is microbially mediated competition (Smith et al. 2006), in which algal exudates stimulate microbial growth and/or respiratory activity. Increased microbial metabolism is suggested to create hypoxic conditions at the interface of corals and algae and, ultimately, to cause the death of coral tissue (Smith et al. 2006).

The microbially mediated competition hypothesis has gained momentum in the literature; however, it has not been tested in the context of key physical (i.e. water flow) and physiological processes (reef metabolism) that occur in the field. Coral tissues experience diel oxygen extremes within their tissues due to coral host and symbiont respiration, and Symbiodinium photosynthesis (Kühl et al. 1995). Coral tissues are hyperoxic during the day (>250\% air saturation) and hypoxic at night $(<2 \%$ air saturation; Kühl et al. 1995). Algal surfaces are also hyperoxic during the day and can reach oxygen concentrations higher than those of corals ( $600 \%$ air saturation; Kühl et al. 1995, Larkum et al. 2003). When corals and algae are in proximity, then, oxygen conditions at their point of contact (zone of interaction) should vary according to the dynamics of oxygen: production by net photosynthesis during the day and consumption of oxygen at night due to respiration.

However, oxygen extremes observed in zones of interaction between corals and algae are inconsistent between studies. Hypoxia was measured in a laboratory setting between massive Porites and algal turf under conditions of low light and no flow (Barott et al. 2011) and attributed to microbial activity. In a study conducted in the field, in ambient flow $\left(8 \mathrm{~cm} \mathrm{~s}^{-1}\right)$, hypoxia was only observed at night (Wangpraseurt et al. 2012). Neither of these studies explicitly tested for the effects of water flow on the maintenance of extreme oxygen conditions.

Water flow likely influences the establishment of extreme oxygen conditions by modulating the thicknesses of the boundary layers formed above organisms. Boundary layers are regions of slow-velocity fluid that are formed by friction when fluid moves over an object (such as the seafloor or an organism). Flow increases away from the surface and, where it reaches $99 \%$ of the bulk water flow, defines the momentum boundary layer (Denny 1988). Diffusive boundary layers (DBLs) are the smallest boundary layers (on the scale of $\mu \mathrm{m}$ to $\mathrm{mm}$ ) and are defined by molecular concentration gradients. The steepness of the gradients is influenced both by water flow and changes in the concentration of solutes (i.e. $\mathrm{O}_{2}$ ).

The biological implications of thinner DBLs are higher rates of mass transfer. Increased mass transfer leads to higher photosynthetic and respiration rates for both corals and algae via increased molecular flux between the organism and the water (Patterson et al. 1991). Additionally, thinner boundary layers in high flow increase the transport of harmful chemical conditions away from coral surfaces (Nakamura et al. 2003, Finelli et al. 2006). Conversely, thicker boundary layers may lead to reduced rates of mass transfer and maintain harmful conditions near the surface of a coral or an alga.

Corals and algae respond physiologically to water flow, and flow can modulate the microenvironmental conditions above corals and algae, so it is likely that water flow modulates the oxygen conditions between coral-algal interactions. The common mounding corals, Porites lobata and Porites lutea (collectively named massive Porites because they are visually indistinguishable), are frequently in contact with algal turf (A.L.B. pers. obs.). Algal turf is a ubiquitous, multi-phyletic functional group composed of dense filaments with canopy heights $<5 \mathrm{~mm}$ (Steneck \& Dethier 1994). In Moorea, French Polynesia, algal turf outcompetes massive Porites more often in low-flow, backreef environments than in areas of higher flow (Brown 2012). The hypothesized mechanisms underlying this pattern are chemically (i.e. microbially) mediated as interactions located in low flow have longer retention times of fluorescein dye and higher bacterial densities than those in high flow (Brown 2012). Algal turfs have previously been shown to negatively affect corals via sediment trapping (Nugues \& Roberts 2003), allelopathy (Jompa \& McCook 2003), and microbially mediated competition (Barott et al. 2011). However, how oxygen conditions differ within algal turf-massive Porites interactions in no, low and high flows is unknown.

This study was conducted to quantify how water flow influences DBL thickness and oxygen conditions within interactions between algal turf and massive Porites. Additionally, the effect of microbial respiration on oxygen conditions was measured within massive Porites-algal turf interactions, which has been rarely quantified, even though microbes are hypothesized to drive decreases in oxygen conditions in 
the zone of interaction (Smith et al. 2006). Three hypotheses were tested. The first was that increased water flow decreases the establishment and maintenance of potentially harmful conditions due to thinner DBLs over the surfaces of algal turf, zones of interaction, and coral. Second, we hypothesized that oxygen conditions in the zone of interaction would be hyperoxic during the day and hypoxic at night, within thicker boundary layers, due to algal turf and coral metabolism. Thirdly, it was hypothesized that microbes affect oxygen conditions above each surface (coral, algal turf, zone of interaction) in both the light and dark. The overall goal of this study was to show the limitations created by the physical environment on the creation, establishment, and maintenance of potentially harmful oxygen extreme conditions in the zone of interaction between corals and algae under realistic flow conditions.

\section{MATERIALS AND METHODS}

This study was conducted in Moorea, French Polynesia $\left(17^{\circ} 52^{\prime} \mathrm{S}, 149^{\circ} 56^{\prime} \mathrm{W}\right)$ at the Richard B. Gump South Pacific Research Station. Cores of interacting algal turf and massive Porites were collected with an underwater pneumatic drill with a diamond-grit hole saw attachment $(6.35 \mathrm{~cm}$ diameter, $3.81 \mathrm{~cm}$ cutting depth; McMaster Carr) from a low-flow, fringing reef on the north shore of Moorea, with light conditions between 800 and $1000 \mu \mathrm{mol}$ photons $\mathrm{m}^{-2} \mathrm{~s}^{-1}$. Intact interactions were used and divided naturally into half algal turf and half massive Porites, with the zone of interaction defined as the point at which the coral was in contact with the algal turf. The removal of intact interactions retained any associated microbial community. Cores were left in the field after drilling for at least $1 \mathrm{wk}$ until coral tissue grew over the edge of the core, which was evidence of healing. Cores were removed from the field and placed in aquaria with running seawater until measurements were completed within $24 \mathrm{~h}$.

\section{Effect of flow on DBL thickness and oxygen concentrations over coral-algal interactions}

Boundary layer thickness, as a function of flow, light, and surface type, was estimated from oxygen concentration profiles measured above the cores of massive Porites-algal turf interactions. Cores were collected from the field $(\mathrm{n}=7)$ as described above and placed in a 41 , temperature-controlled, Plexiglas flume (Fig. 1). The flume was filled with recirculating filtered seawater from the reef (Whirlpool whole house filter, $30 \mu \mathrm{m})$. Flow was created in the
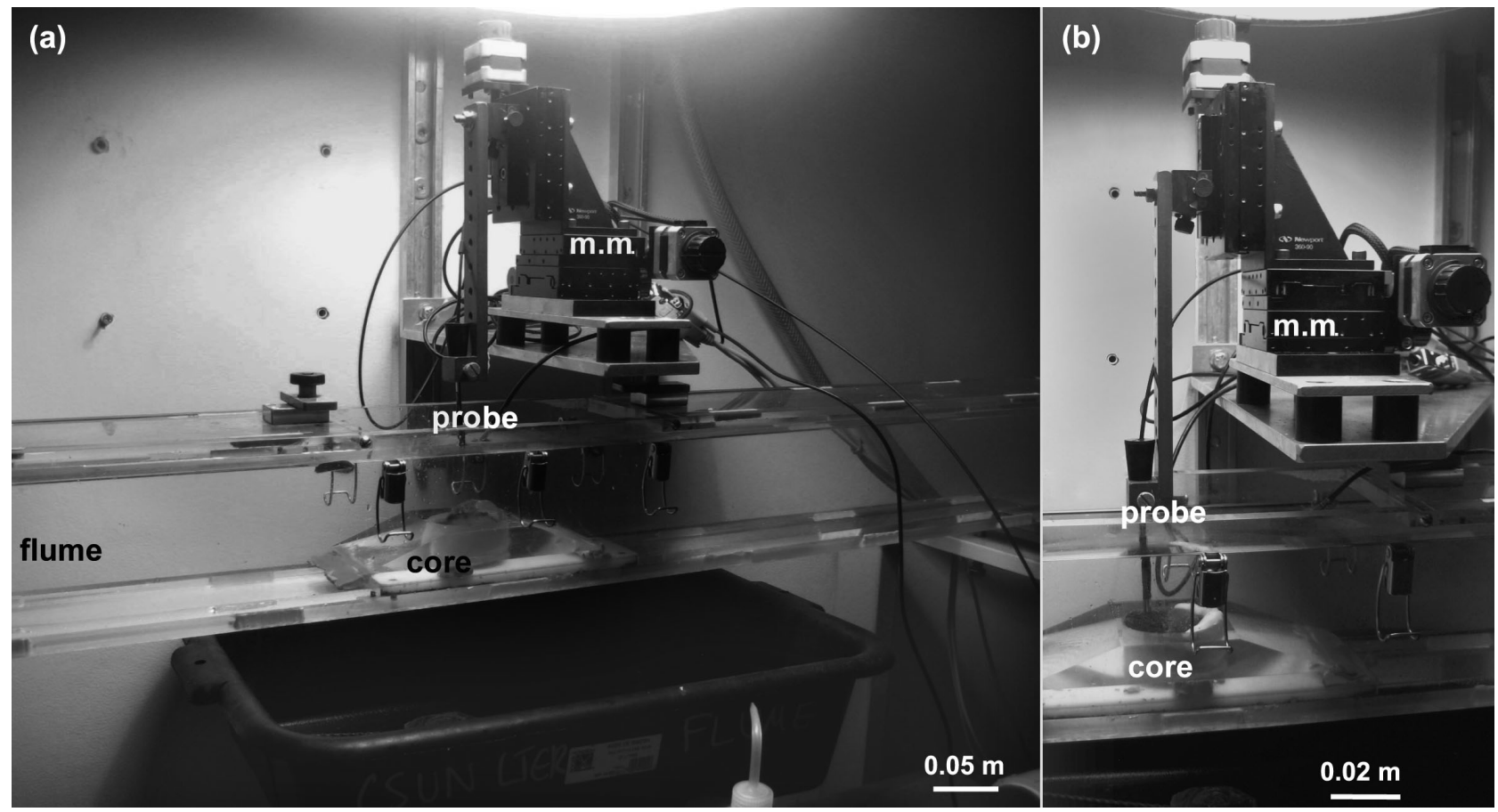

Fig. 1. (A) Flume, micromanipulator (m.m.), oxygen probe, and core (the sample). (B) Closer view of micromanipulator, oxygen probe, and core 
flume using a motor-driven propeller. The flow proceeded through flow straighteners into the upstream end of the working section. At all flow speeds, flow was turbulent (Carpenter \& Williams 2007). The cores were placed in a depression within a Plexiglas ramp on the bottom of the working section $(160 \times 10 \times 12 \mathrm{~cm})$ of the flume to facilitate smooth flows above the surface of the core. The algal turf portion of the core was placed upstream of the coral for each measurement.

Oxygen concentrations were measured with a PreSens needle microsensor oxygen probe (diameter: $<50 \mu \mathrm{m})$ attached to a PreSens Microx TX3 system (PreSens Precision Sensing $\mathrm{GmbH}$ ). The oxygen probe was calibrated using a 2-point calibration with temperature correction in water-saturated air (100\%) and zero oxygen seawater (supersaturated sodium dithionite, $\mathrm{Na}_{2} \mathrm{~S}_{2} \mathrm{O}_{4}$ ). Oxygen concentrations were measured in $\mathrm{mg} \mathrm{l}^{-1}$ with a response time of $1 \mathrm{~s}$ and accuracy of $>90 \%$. Oxygen concentrations were automatically corrected for temperature using a temperature probe (PreSens Precision Sensing $\mathrm{GmbH}$ ), which was concurrently submersed within the flume. Temperature was maintained at ambient seawater temperature in air $\left(26^{\circ} \mathrm{C}\right)$ and was controlled by a chiller (Aqualogic Delta Star) attached to the jacketed section of the flume. Ambient oxygen concentrations were maintained at $182.7 \pm 1.7 \mu \mathrm{mol} \mathrm{O}_{2} \mathrm{l}^{-1}$ during the day and $173.6 \pm 1.5 \mu \mathrm{mol} \mathrm{O} \mathrm{O}^{-1}$ at night by re-filling the flume with filtered seawater twice daily. Oxygen concentrations were converted to $\mu \mathrm{mol} \mathrm{l}^{-1}$ at $27.5^{\circ} \mathrm{C}$ and $36 \mathrm{ppt}$ salinity, which were the conditions in the flume and in the field.

The oxygen probe was attached to a motorized, computer-controlled micromanipulator (ScanController). The micromanipulator was attached securely to a steel shelf above the flume with rubber grommets between the metal and the wall to prevent translation of vibrations. Light measurements were made at the height of the core in the working section of the flume using a $2 \pi$ LiCOR [LI-192] light sensor to ensure that the presence of the micromanipulator did not block the light available to the surface of the cores for profiles completed during the day. The probe was placed at a random location at the surface of either the algal turf, zone of interaction, or coral, and located as close to the surface as possible $(\sim 10 \mu \mathrm{m})$. Oxygen profiles were measured by raising the oxygen probe in incremental steps of $100 \mu \mathrm{m} \mathrm{s}^{-1}$ from the surface to a height of $2500 \mu \mathrm{m}$. At each $100 \mu \mathrm{m}$, the probe paused to read measurements for $1 \mathrm{~s}$. Profiles in the light were measured under saturating light conditions similar to those experienced in the field $\left(800 \mu \mathrm{mol}\right.$ photon $\mathrm{m}^{-2} \mathrm{~s}^{-1}$; Hubbell $1000 \mathrm{~W}$ metal halide light) during the day and in darkness at night above each surface type in 3 different flow regimes. Flow speeds $\left(0,7.7\right.$, and $\left.14.5 \mathrm{~cm} \mathrm{~s}^{-1}\right)$ were chosen based on low- and high-flow speeds measured previously in the backreef using an Acoustic Doppler Profiler, and were calibrated in the flume with an Acoustic Doppler Velocimeter (Nortek AS Vectrino).

Cores were acclimated to flow conditions for $5 \mathrm{~min}$ before measurements began $(n=7)$. Five minutes is an adequate time for boundary layers to develop and for oxygen in tissues to stabilize (Kühl et al. 1995). Each core then was returned to a seawater table, and profiles were re-measured in the dark (at night) above each of the surfaces (alga, zone of interaction, and coral) and at each flow speed. The thickness of the DBL was calculated from oxygen profiles by determining the height at which oxygen concentrations reached $99 \%$ of the bulk oxygen concentration (Jørgensen \& Revsbech 1985). Maximum oxygen concentrations and minimum oxygen concentrations within the DBL were also recorded from the oxygen profile to determine the extent of hypoxia or hyperoxia.

DBL thickness, maximum oxygen, and minimum oxygen concentrations were compared using separate 2-way, repeated measure (RM) MANOVAs on JMP V 5.1. Separate analyses were completed for light and dark measurements. Surface type (algal turf, massive Porites, zone of interaction) and core were treated as between-subject factors. Flow $(0,7.7$, $14 \mathrm{~cm} \mathrm{~s}^{-1}$ ) was treated as a repeated measure, and was crossed with core and surface as within-subject factors. The assumption of sphericity was met for all response variables, and within-subject factors were tested using the Huyn-Feldt Epsilon statistic. When the sphericity assumption was met, exact $F$-values were calculated to test for significance $(\alpha=0.05)$. If it was not met, approximate $F$-values were calculated which accounted for sphericity. For the betweensubject tests, $F$-tests were used.

\section{Effect of microbes on oxygen conditions}

Differences in oxygen concentrations before and after antibiotic addition were quantified to test the hypothesis that microbial activity drives oxygen conditions within coral-algal interactions. Oxygen concentrations were measured using a PreSens blunt end dipping probe (4 $\mathrm{mm}$ diameter), which used a planar oxygen-sensitive foil to detect oxygen and was attached to a PreSens Fibox 3 with a response 
time of $<6 \mathrm{~s}$. The probe was calibrated using the 2-point $(0,100 \%$ air saturation), temperaturecompensated method as described previously.

The oxygen probe was placed $0.5 \mathrm{~mm}$ above each surface. This height was determined previously to be within the DBL over each surface type in low flow. Oxygen concentrations were measured in low flow $\left(7.7 \mathrm{~cm} \mathrm{~s}^{-1}\right)$ above the surface of the coral, the zone of interaction, and the algal turf after the probe had stabilized for 1 to $3 \mathrm{~min}$. Oxygen concentrations were measured for $30 \mathrm{~s}$ at 3 different locations per surface type and then were averaged over time and location to obtain one value for each surface type per core. Measurements were completed both in saturating light conditions (as described previously) and in the dark.

Each core then was placed in a seawater bath with $50 \mu \mathrm{g} \mathrm{ml}^{-1}$ of the broad-spectrum antibiotic ampicillin for $48 \mathrm{~h}$ after the initial measurements (Smith et al. 2006). Water baths were kept in the shade and aerated. Seawater and $50 \mu \mathrm{g} \mathrm{ml}^{-1}$ of ampicillin were replaced every $24 \mathrm{~h}$. After $48 \mathrm{~h}$, post-antibiotic oxygen concentration measurements were completed over the 3 surfaces in both light and dark. A pilot experiment demonstrated that there was no difference in oxygen concentrations from the beginning to end of the $48 \mathrm{~h}$ without addition of antibiotics, indicating that the results observed were due to loss of microbial respiration, not growth of algae or coral $\left(F_{1,10}=3.5, \mathrm{p}=0.1\right)$.

Differences in oxygen concentrations before and $48 \mathrm{~h}$ after antibiotic addition were compared using RM MANOVA. Surface (algal turf, zone of interaction, and coral), light (light/dark), and core were treated as the between-subject factors. Before and after antibiotic treatment was treated as a repeated measure. Because these data were analyzed as a MANOVA with 3 factors, sphericity was not assessed (Quinn \& Keough 2002). Ftests were used for all factors to test for significance.

\section{RESULTS}

\section{Effect of surface and flow on DBL thickness and oxygen concentrations}

Boundary layer thickness significantly decreased as water flow increased, in both the dark ( $\mathrm{p}<0.001$; Table 1, Figs. 2 $\& 3$ ) and the light $(p<0.001$; Table 2,
Table 1. Statistical analysis of differences in the thickness of the diffusive boundary layer (DBL) and minimum oxygen concentrations in the dark above different surfaces (algal turf, zone of interaction, coral) and with flow $(0,7.7,14.5 \mathrm{~cm}$ $\mathrm{s}^{-1}$ ), blocked by core, according to 2 separate repeated measure MANOVAs. Degrees of freedom are listed as numerator, denominator. For the between-subject tests, the multivariate (Mv) F statistic is given; for the within-subject tests the Huyen-Feldt (H-F) epsilon is given

\begin{tabular}{|lrrrr|}
\hline & & $\mathrm{df}$ & $F$ & $\mathrm{p}$ \\
\hline DBL thickness & & & & \\
Between subjects & $\mathbf{M v} \boldsymbol{F}$ & & & \\
Core & 0.630 & 6,12 & 1.260 & 0.344 \\
Surface & 0.710 & 2,12 & 4.260 & 0.04 \\
Within subject & $\underline{\mathbf{H}-\mathbf{F} \boldsymbol{\varepsilon}}$ & & & \\
Flow & 1 & 12,24 & 683.215 & $<0.001$ \\
Flow $\times$ Core & 1 & 4,24 & 8.056 & $<0.001$ \\
Flow $\times$ Surface & & & & \\
& & & & \\
Minimum $\mathbf{O}_{2}$ & $\mathbf{M v} \boldsymbol{F}$ & & & \\
Between subjects & $\mathbf{M . 3 1 7}$ & 6,12 & 0.634 & 0.702 \\
Core & 0.701 & 2,12 & 4.210 & 0.041 \\
Surface & $\underline{\mathbf{H}-\mathbf{F} \boldsymbol{\varepsilon}}$ & & & \\
Within subject & 1 & 2,24 & 145.535 & $<0.001$ \\
Flow & 1 & 12,24 & 0.588 & 0.831 \\
Flow $\times$ Core & 1 & 4,24 & 3.899 & 0.014 \\
Flow $\times$ Surface & & & & \\
\hline
\end{tabular}

Figs. 2 \& 3). Additionally, DBL thickness differed between the surfaces in both the dark ( $p=0.04$; Table 1, Figs. $2 \& 3$ ) and the light ( $p=0.02$; Table 2, Figs. $2 \& 3$ ). The thickest DBLs in both light and dark were under no-flow conditions above all surfaces $(2.4$ to $2.5 \mathrm{~mm})$. DBLs in the light in low-flow conditions were thickest above algal turf $(1.6 \pm 0.1 \mathrm{~mm})$, intermediate above the zone of interaction $(1.3 \pm 0.3 \mathrm{~mm})$, and thinnest above corals $(0.8 \pm 1.4 \mathrm{~mm})$. In the light and in high-flow conditions, DBL thicknesses ranged

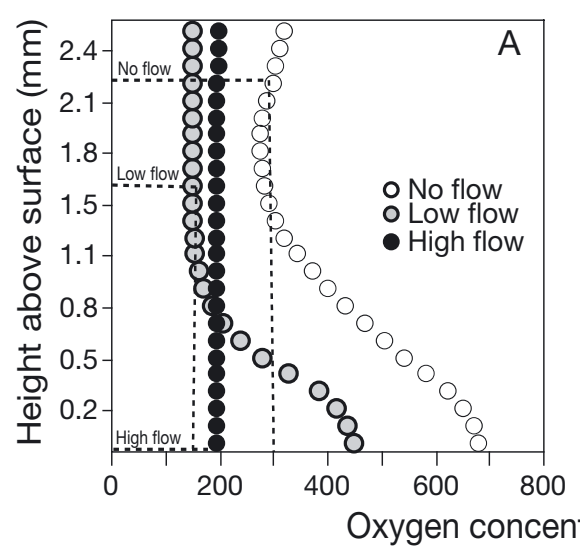

Fig. 2. Characteristic oxygen concentration profiles from the interaction zone between algal turf and massive Porites in (A) light and (B) dark, for high flow $\left(14 \mathrm{~cm} \mathrm{~s}^{-1}\right)$, low flow $\left(7.7 \mathrm{~cm} \mathrm{~s}^{-1}\right)$, and no flow. Dashed lines show the diffusive boundary layer (DBL) thickness at each flow speed for each panel 

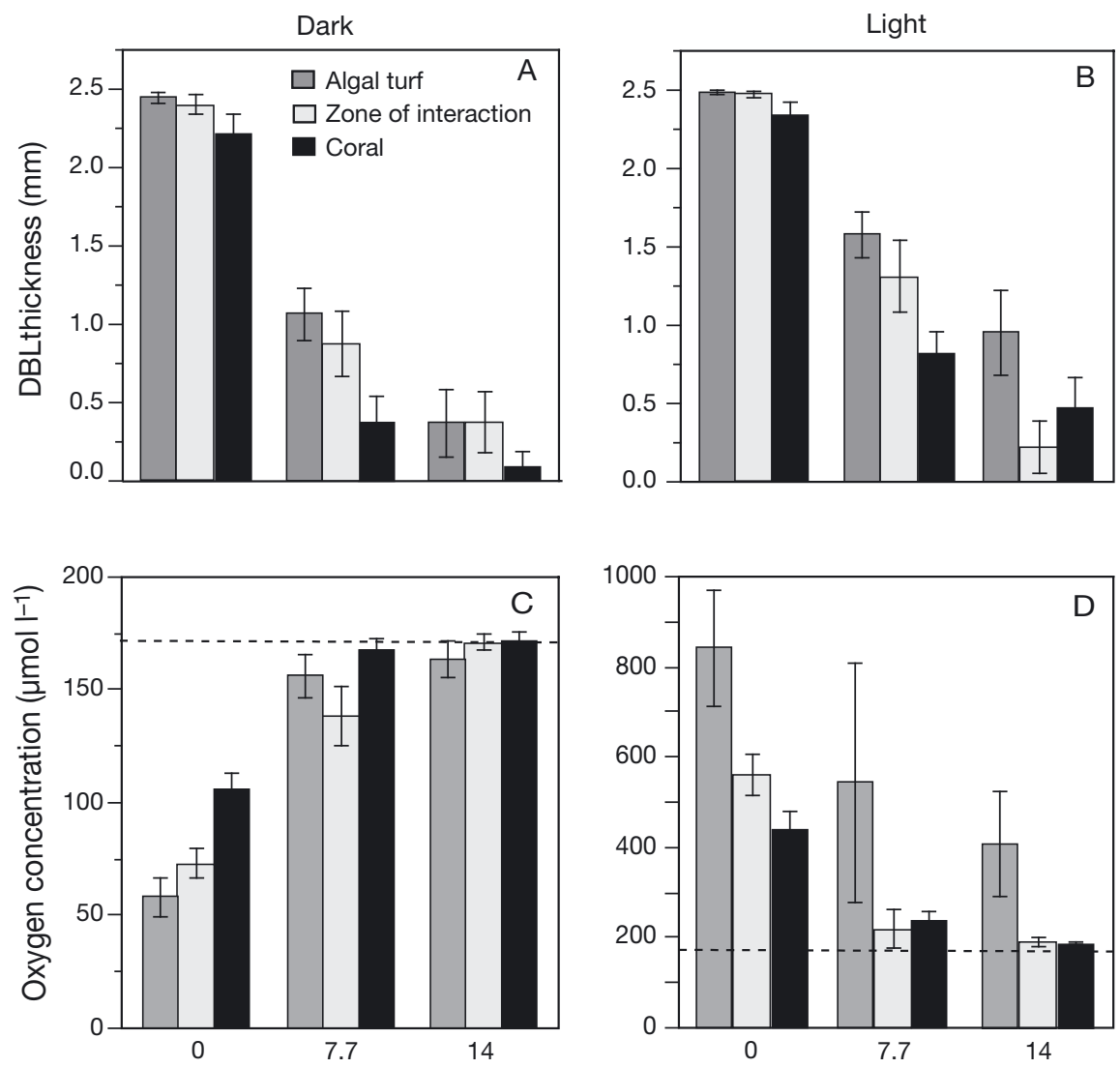

Flow speed $\left(\mathrm{cm} \mathrm{s}^{-1}\right)$

Fig. 3. Mean $( \pm \mathrm{SE})$ diffusive boundary layer (DBL) thickness in (A) dark and (B) light, and corresponding mean $( \pm \mathrm{SE})(\mathrm{C}) \mathrm{min}-$ imum oxygen concentrations within the DBL in the dark and (D) maximum oxygen concentrations within the light. Measurements were made over the surfaces of algal turf, zone of interaction and massive Porites. Dashed line indicates ambient oxygen conditions. In the dark (A and C), flow and surface had significant effects on the measured variable, and there was a flow $x$ surface interaction $(n=7)$. In the light (B and D), DBL thickness significantly decreased with increasing flow, and differed between the surfaces, while maximum oxygen concentration was only significantly affected by water flow $(n=7)$

from $0.2 \pm 0.2$ to $1.0 \pm 0.2 \mathrm{~mm}$ above the surfaces. There was a significant interaction between surface and water flow in the dark due to different responses of surfaces to increases in flow ( $p=0.03$; Table 1). DBL thickness in the dark decreased towards zero as flow increased over the surface of coral (from $0.4 \pm$ 0.2 to $0.1 \pm 0.1 \mathrm{~mm}$ in low to high flow). However, DBLs were detectable in low to high flow over the surfaces of algal turf $(1.1 \pm 0.2$ to $0.4 \pm 0.2 \mathrm{~mm})$ and the zone of interaction $(0.9 \pm 0.2$ to $0.4 \pm 0.2 \mathrm{~mm})$. The DBLs above zones of interaction in the dark were more than twice as thick as the DBLs above corals, but not different from those above algal turf. There was also a significant interaction between flow and core in the dark due to differences in the magnitude of DBL thickness between the different cores $(\mathrm{p}<$ 0.001; Table 1).

The variation in DBL thicknesses was reflected in differences in minimum oxygen in the dark and maximum oxygen in the light over each surface type.
Here, oxygen concentrations will be presented as percentage of ambient concentration (178 $\mu$ mol $\mathrm{O}_{2} \mathrm{l}^{-1}$ ). Hypoxic conditions were observed in no-flow conditions (34 to $61 \%$ air saturation) and increased to ambient concentrations as flow increased, although subsaturated oxygen conditions were observed in low flow as well (80 to $96 \%$ air saturation, $\mathrm{p}<0.001$; Table 1, Fig. 3). Minimum oxygen concentrations in the dark differed above each of the surfaces $(p=0.04)$ and were dependent on flow speed ( $p=0.01$; Table 1 , Fig. 3). Oxygen concentrations in no-flow conditions were lowest above algal turf (34\% air saturation), intermediate over the zone of interaction (42\%), and highest above the coral (61\%). Oxygen concentrations in low flow above the surfaces of the zone of interaction and algal turf were $20 \%$ lower than over coral ( $p=0.03$; Table 1), but they were not different from each other.

Maximum oxygen concentrations in the light were highest in no-flow conditions over all surface types 
and decreased towards ambient with increasing flow ( $p<0.001$; Table 2, Fig. 3). Oxygen concentrations over all the surfaces in high flow were within $5 \%$ of ambient oxygen, except the surface of the algal turf, where oxygen concentrations were consistently highest. Oxygen concentrations increased as flow decreased from high to low flow, and the percent of air saturation ranged from 224 to $298 \%$ (algal turf), 105 to $120 \%$ (zone of interaction), and 103 to $131 \%$ (coral). The highest oxygen conditions were observed in no flow above algal turf $(461 \%)$, then above the zone of interaction (307\%), and then above corals $(242 \%)$. Variation in oxygen concentrations due to the core obscured differences in maximum $\mathrm{O}_{2}$ above the 3 surface types (Table 2).

\section{Effect of microbes on oxygen conditions}

Microbial respiration only had an effect on oxygen conditions in the light. Oxygen concentrations were significantly higher $(9 \%, \mathrm{n}=10)$ in the light following antibiotic addition than measurements completed before antibiotics were added $(\mathrm{p}=0.01$; Fig. 4$)$, but there were no differences in oxygen concentrations before and after antibiotics were added in the dark. Oxygen concentrations in the light were significantly

Table 2. Statistical analysis of differences in the thickness of the diffusive boundary layer (DBL) and maximum oxygen concentrations in the light above different surfaces (algal turf, zone of interaction, coral) and with flow $\left(0,7,14 \mathrm{~cm} \mathrm{~s}^{-1}\right)$, blocked by core, according to 2 separate repeated measure MANOVAs. Degrees of freedom are listed as numerator, denominator. For the between-subject tests, the multivariate (Mv) $F$ statistic is given; for the within-subject tests the Huyen-Feldt (H-F) epsilon is given

\begin{tabular}{|lrrrr|}
\hline & & df & $F$ & $\mathrm{p}$ \\
\hline DBL thickness & & & & \\
Between subjects & $\underline{\mathbf{M v} \boldsymbol{F}}$ & & & \\
$\quad$ Core & 0.507 & 6,12 & 1.015 & 0.460 \\
$\quad$ Surface & 1.019 & 2,12 & 6.112 & 0.015 \\
Within subject & $\underline{\mathbf{H}-\mathbf{F} \boldsymbol{\varepsilon}}$ & & & \\
Flow & 25.101 & 2,11 & 138.055 & $<0.001$ \\
Flow $\times$ Core & 1 & 12,24 & 0.811 & 0.637 \\
Flow $\times$ Surface & 1 & 4,24 & 2.141 & 0.107 \\
& & & & \\
Maximum $\mathbf{O}_{2}$ & & & & \\
Between subjects & $\underline{\mathbf{M v} \boldsymbol{F}}$ & & & \\
Core & 0.457 & 6,12 & 0.914 & 0.517 \\
Surface & 0.506 & 2,12 & 3.036 & 0.086 \\
Within subjects & $\underline{\mathbf{H}-\mathbf{F} \boldsymbol{\varepsilon}}$ & & & \\
Flow & 1 & 2,24 & 26.539 & $<0.001$ \\
Flow $\times$ Core & 1 & 12,24 & 1.050 & 0.439 \\
Flow $\times$ Surface & 1 & 4,24 & 0.659 & 0.627 \\
\hline
\end{tabular}

higher than in the dark ( $\mathrm{p}<0.001$; Table 3, Fig. 4), and higher above algal turf (during the day) and lower (at night) than above zones of interaction and corals ( $\mathrm{p}<0.001$; Table 3, Fig. 4).

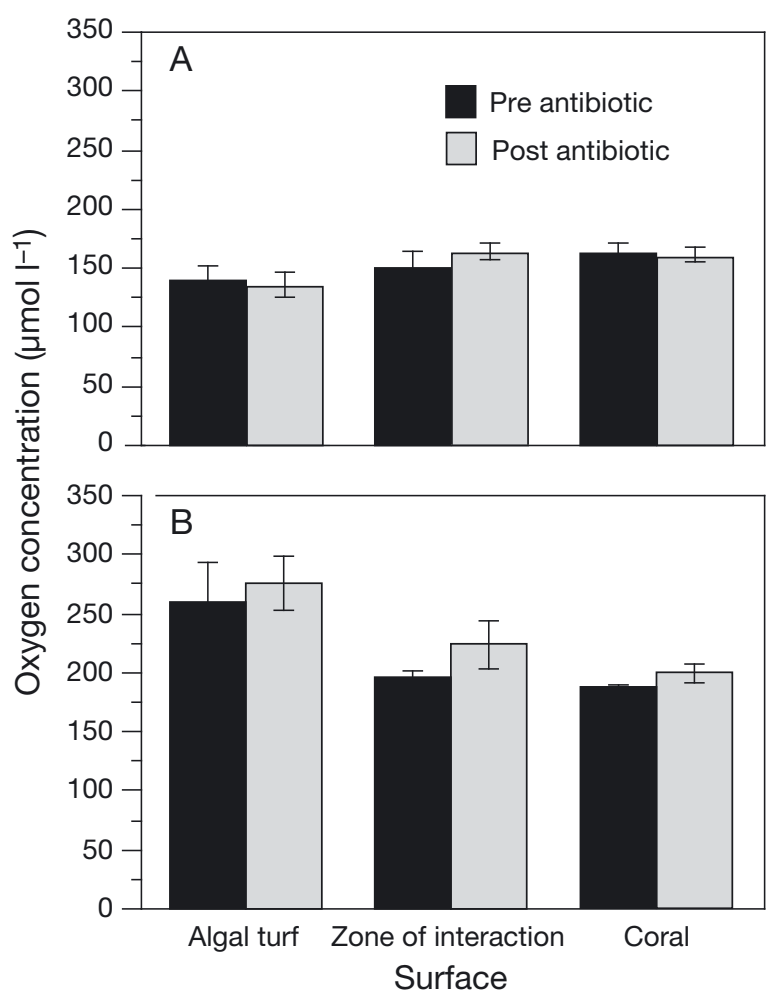

Fig. 4. Mean $( \pm \mathrm{SE})$ oxygen concentration before and $48 \mathrm{~h}$ after antibiotic addition in (A) dark and (B) light. Antibiotic addition only significantly influenced oxygen concentrations in the light $(\mathrm{n}=10)$

Table 3. Results of 3-way repeated measure MANOVA comparing surfaces (algal turf, zone of interaction, coral surface), light versus dark (light), and antibiotic addition (preversus post-treatments). Degrees of freedom are listed as the numerator and denominator degrees of freedom. Mv F: multivariate $F$ statistic

\begin{tabular}{|lrrrr|}
\hline & Mv $F$ & df & Exact $F$ & $\mathrm{p}$ \\
\hline Between subjects & & & & \\
Core & 0.162 & 9,45 & 0.810 & 0.609 \\
Surface & 0.060 & 2,45 & 1.341 & 0.272 \\
Light & 2.334 & 1,45 & 105.063 & $<0.001$ \\
Surface $\times$ Light & 0.573 & 2,45 & 12.895 & $<0.001$ \\
& & & & \\
Within subjects & & & & \\
$\quad$ Antibiotic & 0.086 & 1,45 & 3.874 & 0.055 \\
Antibiotic $\times$ Core & 0.264 & 9,45 & 1.319 & 0.254 \\
Antibiotic $\times$ Surface & 0.013 & 2,45 & 0.295 & 0.746 \\
Antibiotic $\times$ Light & 0.166 & 1,45 & 7.448 & 0.009 \\
Antibiotic $\times$ Surface & 0.025 & 2,45 & 0.555 & 0.578 \\
$\quad \times$ Light & & & & \\
\hline
\end{tabular}




\section{DISCUSSION}

Coral reefs are dynamic environments in which water flow can dictate how organisms interact. This study is the first to quantify how water flow may constrain the effectiveness of microbially mediated mechanisms of competition between corals and algae by modulating DBL thickness and oxygen concentrations above the zone of interaction between algal turf and coral. Furthermore, these results showed no evidence of hypoxia caused by microbes and suggest that the metabolic activity of the algal turf during the day drives the dominant changes in oxygen concentrations.

The results of this study do not support the microbially mediated competition hypothesis, which suggests that low-oxygen concentrations at the zone of interaction are a result of microbial activity (Smith et al. 2006). There was no evidence of the hypothesized hypoxic conditions created by microbes, even in zero flow conditions (Smith et al. 2006). The oxygen concentrations above the zone of interaction reflected the metabolic processes that occurred in the light (photosynthesis and respiration) and the dark (respiration). Hypoxic and hyperoxic conditions were present only in low- and no-flow conditions, at flow speeds where DBL thicknesses were measurable. In high flow, when DBLs were not detectable, oxygen concentrations above the zone of interaction were not different from ambient oxygen concentrations. The current study took into account ecologically relevant field conditions (i.e. flow and light), and the results were consistent with field data that showed similar oxygen conditions at the zone of interaction between algal turf and massive Porites during the day (hyperoxic) and at night (hypoxic; Wangpraseurt et al. 2012).

Water flow modulated the establishment and maintenance of oxygen concentrations, but light versus dark influenced the types of oxygen extremes. The light conditions in previous studies likely are one factor that influenced the outcome of their experiments (Smith et al. 2006, Barott et al. 2009, 2011). For example, low-light levels reported in previous studies (Smith et al. 2006, Barott et al. 2009, 2011) may not have saturated algal and coral photosystems, which could have led to lower rates of photosynthesis (Porter et al. 1989). Additionally, low-light conditions may result in greater oxygen consumption than oxygen production when in conjunction with lower symbiont densities at the margin of the coral due to growth (Shick \& Dykens 1985) or bleaching (Porter et al. 1989). Thus, low light would affect the physiology of the coral holobiont and the algae in contact with the coral, which could cause the localized hypoxia noted in previous studies (Smith et al. 2006). An alternative explanation for previously reported hypoxic conditions (Smith et al. 2006) could be due to different qualities of dissolved organic carbon produced by different collections of algal turfs in contact with the coral (Jompa \& McCook 2003, Haas et al. 2011, Nelson et al. 2013). However, bacterial respiration in the current study only decreased oxygen concentrations in the light.

The thick, dense canopy of algal turf likely retained hyperoxic (light) and hypoxic (dark) conditions, and drove the similarities in DBL thicknesses and the degree of hypoxia/hyperoxia above the algal turf and the zone of interaction in low flow (Carpenter \& Williams 1993). Additionally, the high metabolic output of algal turfs relative to corals and microbes suggests that algal turf photosynthesis and respiration may determine oxygen concentrations to a greater degree than microbial respiration. Comparisons of net photosynthetic rates by algal turf versus respiration rates of microbes incubated in algal exudates show higher algal oxygen production rates per area $\left(2.5 \mu \mathrm{mol} \mathrm{O}_{2}\right.$ produced $\mathrm{cm}^{-2} \mathrm{~h}^{-1}$; Carpenter \& Williams 2007) than oxygen consumption by bacteria fueled by algal exudates, which can range from 0.01 to $0.07 \mu \mathrm{mol} \mathrm{O}$ uptake $\mathrm{cm}^{-2} \mathrm{~h}^{-1}$ (C. Nelson pers. comm.). Coral net photosynthetic rates $\left(0.21 \mu \mathrm{mol} \mathrm{O}_{2}\right.$ produced $\mathrm{cm}^{-2} \mathrm{~h}^{-1}$; Anthony et al. 2008) are less than algal turf production, but are higher than microbial uptake, indicating that it is unlikely that microbialactivity-driven hypoxia could lead to coral tissue necrosis. These estimates further suggest that algal turf metabolism likely affects the concentration of oxygen in the zone of interaction during the day.

Oxygen extremes have the potential to detrimentally affect coral physiology and may contribute to a breakdown of the symbiosis between corals and algae via coral bleaching (Ulstrup et al. 2005, Finelli et al. 2006). Additionally, sustained anoxic and hypoxic oxygen conditions above corals from microbial activity in the sediment can lead to coral tissue death (Weber 2009). Hyperoxia, as well, may create stressful conditions that can lead to bleaching due to oxidative stress (Hoegh-Guldberg \& Smith 1989, Lesser 1996, Downs et al. 2002, Lesser 2006, Mass et al. 2010). Although hyperoxic conditions occur daily within the tissues of corals and in the DBL over the coral surface (Kühl et al. 1995, Wangpraseurt et al. 2012, present study), exposure to hyperoxic water leads to decreased photosynthetic efficiency in corals (Finelli et al. 2006, Mass et al. 2010). High-oxygen conditions experienced by 
corals in contact with algal turf, for example, when oxygen bubbles form over the surface of the algal canopy and encroach upon the zone of interaction (authors' pers. obs.), may push the hyperoxic tolerance of corals beyond their threshold.

These results have implications for interactions between corals and algae located in reefs with heterogeneous flows. Flow variability and retention of hypoxic or hyperoxic conditions will regulate the susceptibility of corals to oxygen extremes, which we suggest are driven by algal turf metabolism, not microbes. Hyperoxic or hypoxic conditions likely build up quickly within interactions located in low flow because of a combination of the high oxygen production of algal turf and thick boundary layers in which retention times of water are on the order of minutes (5.17 $\pm 1.8 \mathrm{~min}$; Brown 2012). Long retention times within low-flow interactions may also result in the retention of other chemicals derived from the alga (or coral), such as secondary metabolites (Rasher \& Hay 2010a), pathogenic bacteria (Nugues et al. 2004), or ciliate infection (Bender et al. 2012). How water flow influences lipid-soluble allelochemicals or coral disease was not the focus of this study, and further investigation is needed to quantify the effects of water flow on the effectiveness of other modes of coral-algal competition. For example, it is possible that high flow can increase coral-algal contact and facilitate the transfer of lipid soluble allelochemicals from algae to corals (Rasher \& Hay 2010b).

Water flow is variable on a reef on several spatial scales, and only in areas that generally experience low-flow conditions will water-soluble chemically mediated mechanisms of competition be effective. Regions of the backreef that are most likely to experience low flow ( 0 to $7.7 \mathrm{~cm} \mathrm{~s}^{-1}$ ) are consistently the downstream sides of coral bommies (Brown 2012) and on short bommies (30 to $40 \mathrm{~cm}$ tall; Lenihan et al. 2008), as well as within gaps or crevices. This study highlights how water flow mitigates potential chemical effects of algae on corals by decreasing the thickness of the DBL over the zone of interaction, likely rendering the chemical mechanisms underlying competition between corals and algae ineffective. Therefore, within a heterogeneous reef environment, the water flow context modulates the microenvironmental conditions between corals and algae and regulates the effects of algae on corals.

Acknowledgements. We thank P. J. Edmunds and C. Nelson, V. W. Moriarty, M. D. Johnson, S. A. Swanson, and J. C. Gowan for laboratory and field assistance. The project was funded under the MCR LTER OCE 04-17412/OCE 10-26851 grant, the Gordon and Betty Moore Foundation and California State University, Northridge. This is Contribution No. 198 from the CSUN Marine Biology Program.

\section{LITERATURE CITED}

Anthony KR, Kline D, Diaz-Pulido G, Dove S, Hoegh-Guldberg $O$ (2008) Ocean acidification causes bleaching and productivity loss in coral reef builders. Proc Natl Acad Sci USA 105:17442-17446

Barott K, Smith J, Dinsdale E, Hatay M, Sandin S (2009) Hyperspectral and physiological analyses of coral-algal interactions. PLoS ONE 4:e8043

> Barott KL, Rodriguez-Brito B, Janouškovec J, Marhaven K, Smith JE, Keeling P, Rohwer F (2011) Microbial diversity associated with four functional groups of benthic reef algae and the reef-building coral Montastraea annularis. Environ Microbiol 13:1192-1204

> Bellwood DR, Hughes T, Folke C, Nystrom M (2004) Confronting the coral reef crisis. Nature 429:827-833

- Bender D, Diaz-Pulido G, Dove S (2012) Effects of macroalgae on corals recovering from disturbance. J Exp Mar Biol Ecol 429:15-19

Brown A (2012) The influence of water flow on mechanisms underlying coral-algal interactions. California State University, Northridge, CA

$>$ Bruno JF, Sweatman H, Precht W, Selig E, Schutte V (2009) Assessing evidence of phase shifts from coral to macroalgal dominance on coral reefs. Ecology 90:1478-1484

Carpenter RC, Williams S (1993) Effects of algal turf canopy height and microscale substratum topography on profiles of flow speed in a coral forereef environment. Limnol Oceanogr 38:687-694

> Carpenter RC, Williams S (2007) Mass transfer limitation of photosynthesis of coral reef algal turfs. Mar Biol 151: 435-450

Denny MW (1988) Biology and the mechanics of the waveswept environment. Princeton University Press, Princeton, NJ

> Downs CA, Fauth J, Halas J, Dustan P, Bemiss J, Woodley C (2002) Oxidative stress and seasonal coral bleaching. Free Radic Biol Med 33:533-543

Finelli C, Helmuth B, Pentcheff N, Wethey D (2006) Water flow influences oxygen transport and photosynthetic efficiency in corals. Coral Reefs 25:47-57

> Haas AF, Nelson CE, Wegley Kelly L, Carlson CA and others (2011) Effects of coral reef benthic primary producers on dissolved organic carbon and microbial activity. PLoS ONE 6:e27973

> Hoegh-Guldberg O, Smith GJ (1989) The effect of sudden changes in temperature, light and salinity on the population density and export of zooxanthellae from the reef coral Stylophora pistillata Esper and Seriatopora hystrix Dana. J Exp Mar Biol Ecol 129:279-303

> Hughes TP (1994) Catastrophes, phase shifts, and largescale degradation of a Caribbean coral reef. Science 265: $1547-1551$

Jompa J, McCook L (2003) Contrasting effects of turf algae on corals: massive Porites spp. are unaffected by mixedspecies turfs, but killed by the red alga Anotrichium tenue. Mar Ecol Prog Ser 258:79-86

Jørgensen B, Revsbech N (1985) Diffusive boundary layers and the oxygen uptake of sediments and detritus. Limnol Oceanogr 30:111-122 
Kühl M, Cohen Y, Dalsgaard T, Jorgensen BB, Revsbech NP (1995) Microenvironment and photosynthesis of zooxanthellae in scleractinian corals studied with micorsensors for $\mathrm{O}_{2}, \mathrm{pH}$ and light. Mar Ecol Prog Ser 117:159-172

Larkum AWD, Koch EM, Kühl M (2003) Diffusive boundary layers and photosynthesis of the epilithic algal community of coral reefs. Mar Biol 142:1073-1082

Lenihan H, Adjeroud M, Kotchen M (2008) Reef structure regulates small-scale spatial variation in coral bleaching. Mar Ecol Prog Ser 370:127-141

Lesser MP (1996) Elevated temperatures and ultraviolet radiation cause oxidative stress and inhibit photosynthesis in symbiotic dinoflagellates. Limnol Oceanogr 41: 271-283

Lesser MP (2006) Oxidative stress in marine environments: biochemistry and physiological ecology. Annu Rev Physiol 68:253-278

Mass T, Genin A, Shavit U, Grinstein M, Tchernov D (2010) Flow enhances photosynthesis in marine benthic autotrophs by increasing the efflux of oxygen from the organism to the water. Proc Natl Acad Sci USA 107: 2527-2531

McCook L, Jompa J, Diaz-Pulido G (2001) Competition between corals and algae on coral reefs: a review of evidence and mechanisms. Coral Reefs 19:400-417

Moberg F, Folke C (1999) Ecological goods and services of coral reef ecosystems. Ecol Econ 29:215-233

Nakamura T, Yamasaki H, Van Woesik R (2003) Water flow facilitates recovery from bleaching in the coral Stylophora pistillata. Mar Ecol Prog Ser 256:287-291

Nelson C, Goldberg S, Wegley Kelly L, Haas A, Smith JE, Rohwer F, Carlson CA (2013) Coral and macroalgal exudates vary in neutral sugar composition and differentially enrich bacterioplankton lineages. ISME J 7: $1-18$

Nugues M, Roberts C (2003) Coral mortality and interaction with algae in relation to sedimentation. Coral Reefs 22: 507-516

Editorial responsibility: Brian Helmuth, Nahant, Massachusetts, USA
Nugues M, Smith G, Hooidonk R (2004) Algal contact as a trigger for coral disease. Ecol Lett 7:919-923

Patterson M, Sebens K, Olson R (1991) In situ measurements of flow effects on primary production and dark respiration in reef corals. Limnol Oceanogr 36:936-948

Porter JW, Fitt W, Spero H, Rogers C, White M (1989) Bleaching in reef corals: physiological and stable isotopic responses. Proc Natl Acad Sci USA 86:9342-9346

Quinn G, Keough M (2002) Experimental design and data analysis for biologists. Cambridge University Press, Cambridge

> Rasher DB, Hay M (2010a) Chemically rich seaweeds poison corals when not controlled by herbivores. Proc Natl Acad Sci USA 107:9683-9688

Rasher DB, Hay (2010b) Seaweed allelopathy degrades the resilience and function of coral reefs. Commun Integr Biol 3:564-566

River GF, Edmunds PJ (2001) Mechanisms of interaction between macroalgae and scleractinians on a coral reef in Jamaica. J Exp Mar Biol Ecol 261:159-172

Shick J, Dykens J (1985) Oxygen detoxification in algalinvertebrate symbioses from the Great Barrier Reef. Oecologia 66:33-41

Smith JE, Shaw M, Edwards RA, Obura D and others (2006) Indirect effects of algae on coral: algae-mediated, microbe-induced coral mortality. Ecol Lett 9:835-845

> Steneck R, Dethier M (1994) A functional group approach to the structure of algal-dominated communities. Oikos 69:476-498

> Ulstrup KE, Hill R, Ralph PJ (2005) Photosynthetic impact of hypoxia on in hospite zooxanthellae in the scleractinian coral Pocillopora damicornis. Mar Ecol Prog Ser 286: 125-132

- Wangpraseurt D, Weber M, Røy H, Polerecky L, De Beer D, Suharsono, Nugues MM (2012) In situ oxygen dynamics in coral-algal interactions. PLoS ONE 7:e31192

Weber M (2009) How sediment damages corals. PhD dissertation, Max Planck Institute, Bremen

Submitted: December 12, 2012; Accepted: July 1, 2013

Proofs received from author(s): August 16, 2013 